\title{
Mental Health, Substance Abuse, and Health Behavior Services in Patient-Centered Medical Homes
}

\author{
Rodger Kessler, PhD, Benjamin F. Miller, PsyD, Mark Kelly, BA, \\ Debbie Graham, MPH, Amanda Kennedy, PharmD, Benjamin Littenberg, MD, \\ Charles D. MacLean, MD, Constance van Eeghen, DrPH, \\ Sarah Hudson Scholle, MPH, DrPH, Manasi Tirodkar, PhD, \\ Suzanne Morton, MBA, MPH, and Wilson D. Pace, MD
}

Purpose: The purpose of this study was to understand mental health, substance use, and health behavior activities within primary care practices recognized by the National Committee for Quality Assurance as patient-centered medical homes (PCMHs).

Methods: We identified 447 practices with all levels of National Committee for Quality Assurance PCMH recognition as of March 1, 2010. We selected the largest practice from multisite groups, and 238 practices were contacted. We received 123 responses, for a $52 \%$ response rate. A 40 -item web-based survey was collected.

Results: Of PCMH practices, $42 \%$ have a behavioral health clinician on site; social workers were the most frequent category of provider delivering behavioral services. There are also were care managers- distinct from behavioral health clinician —at $62 \%$ of practices. Surveyed practices were less likely to have procedures for referrals, communication, and patient scheduling for responding to mental health and substance use services than for other medical subspecialties (50\% compared with $73 \%$ for cardiology and $69 \%$ for endocrinology). More than half of practices (62\%) reported using electronic, standardized depression screening and monitoring; practices were less likely to screen for substance use than mental health. Among the practices, 54\% used evidence-based health behavior protocols for mental health and substance use conditions. Practices reported that lack of reimbursement, time, and sufficient knowledge were obstacles. Practices serving a higher proportion of low-income patients performed more mental health organizational and clinical activities.

Conclusions: In PCMHs, practice organization and response to behavioral issues seem to be less well developed than other types of medical care. These results support further efforts to develop wholeperson care in the PCMH, with greater emphasis on access to and coordination of mental health, substance abuse, and health behavior services. Focusing primary care practices on this aspect of wholeperson care will benefit from program sponsors' support and rewarding better integration with behavioral health. (J Am Board Fam Med 2014;27:637-644.)

Keywords: Primary Health Care; Delivery of Health Care, Integrated; Health Behavior; Mental Health; Substance Abuse

Even though primary care is the setting for a large portion of care for behavioral health problems (defined here as care for mental health, substance use

This article was externally peer reviewed.

Submitted 16 January 2014; revised 23 April 2014; accepted 2 May 2014.

From the Department of Family Medicine (RK, MK), Department of General Internal Medicine (AK, BL, CDM, CVE), University of Vermont College of Medicine, Burlington; the University of Colorado, Denver, School of Medicine, Denver (BFM, WP); the National Committee for Quality Assurance, Washington, DC (SHS, MT, SM); and the American Academy of Family Physicians, Leawood, KS (DG, WDP). disorders, and health behaviors), these problems are often inadequately addressed in primary care. ${ }^{1-3}$ Little has been written about current behavioral health clinician capacity in primary care. It has been suggested that less than $10 \%$ of psychologists practicing work in primary care settings. ${ }^{4}$

Funding: Patient-Centered Primary Care Collaborative (PCPCC).

Conflict of interest: none declared.

Corresponding author: Rodger Kessler, PhD, CCTS, University of Vermont College of Medicine, 89 Beaumont Ct, Given Courtyard 4th Fl., Burlington, VT 05405 (E-mail: Rodger.Kessler@uvm.edu). 
Kathol $^{5}$ estimates that less than $10 \%$ of the behavioral health workforce practices in primary care. Data concerning the percentage of primary care practices with integrated behavioral health are unavailable, except about services in federally qualified health centers (FQHCs). Lardiere et $\mathrm{al}^{6}$ report $70 \%$ of FQHCs provide behavioral services, $20 \%$ provide substance abuse services, and $20 \%$ provide both.

The growing adoption of the patient-centered medical home (PCMH) model of care offers the potential for improving how primary care practices address the behavioral health needs of their patients. The PCMH model calls for practices to reorganize to improve whole-patient care. ${ }^{7}$ Yet there are still concerns that barriers and changes at multiple levels that need to occur for the potential to be recognized. ${ }^{8}$

A recent complimentary set of joint principles for the PCMH specify that behavioral health should be fully integrated into the PCMH. ${ }^{9}$ The principles align closely with the categories agreed on in the initial PCMH joint principles published in 2007. ${ }^{9}$ This position has been endorsed by the following organizations: the American Academy of Family Physicians (AAFP), the AAFP Foundation, the American Board of Family Medicine, the Society of Teachers of Family Medicine, the North American Primary Care Research Group, the Association of Departments of Family Medicine, and the Association of Family Medicine Residency Directors. There is a great deal of planning and implementation of mental health substance abuse and health behavior services into PCMHs, ${ }^{10,11}$ seemingly in response to a number of factors, including increased recognition of need ${ }^{7}$ and provider frustration with the established lack of access to behavioral health services for primary care patients.

There is little information to help gauge the effect of these efforts on how PCMH practices address the behavioral health needs of their patients. The purpose of this study was to explore how early adopters of the PCMH model address behavioral health care.

The Collaborative Care Research Network, a subnetwork of the AAFP National Research Network, worked with the National Committee for Quality Assurance (NCQA) to survey NCQA-recognized PCMH practices to assess current clinical and organizational response to patients' behavioral health issues, identify barriers to implementation of the services, and compare these to care for general medical needs.

\section{Methods \\ Participants}

All practices that received recognition under NCQA's 2008 Physician Practice ConnectionsPCMH program as of March 1, 2010, were eligible $(n=447)$. When an organization contained multiple practice sites, only the site that had the most providers received the survey. Because we wanted responses to generate a sense of how practices organized care, we were concerned that including multiple sites within the same larger organization would introduce bias. We therefore selected the largest practice in each organization as an exemplar of the entire practice organization. As a result, 238 practice sites were surveyed. The survey was addressed to a physician or administrative contact at the practice.

To be considered for recognition by the NCQA, practices voluntarily complete a web-based survey and attach documentation to support their responses. Trained surveyors review the documentation, and $5 \%$ of applications receive an on-site audit. All applications undergo 3 rounds of internal review. In the 2008 version of the standards, practices could achieve 3 levels of recognition based on the total score as well as their performance on 10 "must pass" elements. The NCQA recognizes practices as level 1, 2, or 3; increasing level corresponds to increasing levels of implementation of PCMH processes. While the 2008 version of NCQA's standards for the PCMH did not explicitly address mental health and substance use and health behavior elements, subsequent versions of the standards presented in 2011 and 2014 place more emphasis on mental health and substance abuse and raise expectations for how practices should integrate behavioral health interventions into routine care.

\section{Measures}

The research team, with members from the Collaborative Care Research Network and NCQA, constructed a survey with 48 items in 4 categories: clinical activity, organizational responses, patient engagement, and identified barriers. Patient engagement data are reported in another article. ${ }^{12}$ The research team, headed by the University of 
Vermont, initially developed the survey tool, and then it was reviewed by members of the senior research team at the AAFP's National Research Network and the research team at NCQA. The survey was field tested with clinical leaders in 8 primary care practices and then revised.

\section{Mental Health Organization and Clinical Index}

Based on Peek's ${ }^{13}$ observation that care is multidimensional and is both a clinical and organizational activity, the research team constructed 2 indices from items contained in the survey (Online Appendix 1). We categorized items as related to the organization of care delivery or to clinical care. This resulted in a 12-question mental health organizational index (Online Appendix 2) with a maximum score of 24 points and a second, 9-item mental health clinical index (Online Appendix 3) with a maximum score of 18 points. Question responses of "yes, works well" received 2 points, a response of "yes, needs improvement" received 1 point, and a "no" response received 0 points. For questions with only 2 options, "yes" responses received 2 points and "no," 0 points.

\section{Other Dimensions Surveyed and Reported}

The survey asked a set of questions (questions 2 to 6 in Online Appendix 1) that contrasted operational procedures concerning referral, scheduling, and communication used when focusing on behavioral health issues with the same procedures for endocrinology and cardiology, which were selected because of their high frequency of referral and communication with primary care practices. Respondents also were asked to rate the degree to which 4 barriers were problems concerning implementing behavioral health in primary care using a 4-point scale (question 13 in Online Appendix 1; full measure).

\section{Survey Procedures}

Before conducting the survey, NCQA E-mailed each practice leader to announce the forthcoming survey. The identified respondents were contacted by E-mail with an invitation to complete the survey online. The E-mail contained a link directing them to the survey and instructions for completing the survey. Two weeks following the E-mail invitation, a paper version of the survey was sent to nonrespondents. The paper version was accompanied by a cover letter explaining the purpose of the survey and a postage-paid return envelope. The cover letter also included instructions for how to complete the online version of the survey if participants chose to do so. The research team subsequently attempted to contact nonrespondent practices' contact person identified from the NCQA database by phone to request their participation or to obtain survey results over the phone, which generated 5 additional responses.

\section{Analytical Plan}

SAS software version 9.2 (SAS, Inc., Cary, NC) was used for data analysis. Participants who did not complete all the questions within an index were eliminated from the index analysis because they could not achieve full scoring. We present descriptive statistics for practice demographic characteristics and individual questions. $\chi^{2}$ Tests were used to determine whether any significant differences existed between respondents and nonrespondents on any practice demographic characteristics. To compare referrals and communication for mental health specialties versus cardiology and endocrinology specialties, we used a repeated measures logistic regression analysis. We used analysis of variance to test for differences in the mental health organization and clinical indices by practice demographic characteristics. Because of the small number of level 2 NCQA-certified practices, levels 1 and 2 were collapsed into a single variable and compared with level 3 practices. Significance level of $P=0.05$ was used for all analyses.

\section{Results}

We received 123 responses, for a 52\% response rate. A total of 115 surveys were collected electronically and the rest by phone and mail. The practices were located in 24 states, and the highest concentration came from states with active PCMH demonstration programs (New York, Pennsylvania, and New Jersey).

Responders did not differ significantly from nonrespondents in recognition level, practice size, specialty, or location (Table 1). About half of the responding practices were small $(<5$ physicians, $55 \%)$, and $12(10 \%)$ were FQHCs or community health centers. Over half had the highest level of NCQA 2008 PCMH recognition (level 3, 56\%); $7 \%$ had level 2 recognition and $37 \%$ had level 1 . Of practices, $42 \%$ reported the presence of a behav- 
Table 1. Practice Demographic Characteristics of the Sample $(\mathrm{n}=\mathbf{1 2 3})$

\begin{tabular}{lc}
\hline Characteristics & Practices (\%) \\
\hline$<5$ Physicians & 55 \\
NCQA recognition level & 44 \\
1 or 2 & 56 \\
3 & \\
Ownership & 50 \\
Physician owned & 40 \\
Other & 33 \\
$>$ 20\% of patients with Medicaid or other & \\
$\quad$ public insurance or no insurance & 37 \\
Practices with more than one location & \\
Specialty & 22 \\
Internal medicine only & 40 \\
Family practice only & 6 \\
Pediatrics only & 25 \\
Combination & 6 \\
Other specialty &
\end{tabular}

NCQA, National Committee for Quality Assurance.

ioral health clinician-a psychiatrist, psychologist, counselor, social worker, or certified substance use counselor-on site as part of the practice staff; $63 \%$ had a care manager. Table 2 summarizes the frequencies of behavioral providers in the practices and engagement in clinical and organizational practice activities.

Less than half of surveyed practices had behavioral health practitioners. Practices were more likely to have care managers than psychiatrists, psychologists, and social workers combined; substance abuse clinicians were less than half as frequent as psychologists and social workers. Scheduling processes for the behavioral health clinicians are the same as other practice providers only a third of the time $(36 \%)$, and same-day appointments are available less than $30 \%$ of the time (28\%). The availability of evidence-based protocols for mental health, substance abuse, and health behavior presentations was identified in 54\% of practices. Protocols for smoking cessation were present in $71 \%$ of practices, obesity in 59\%, insomnia in $38 \%$, and headaches in $34 \%$. About $62 \%$ of practices reported recording results of depression screening and monitoring in an electronic data system.

Table 3 compares practice processes between behavioral health and endocrinology and cardiology. Questions 6 through 12 in Online Appendix 1 identify the questions used as comparison. Fewer practices report having standardized referral pro- cesses for mental health and substance use issues compared with cardiology and endocrinology. In addition, two thirds of practices report using a formal depression screening tool, and $62 \%$ report recording those data in an electronic data system. Of those practices that used behavioral health screening, practices were more likely to screen for depression $(80 \%)$ than for alcohol $(71 \%)$ or substance use $(65 \%)$. Insurance status was related to both the mental health organizational and clinical indices (Tables 4 and 5). Practices serving $>20 \%$ of patients with Medicaid, other public insurance, or no insurance were more likely to perform these activities.

Respondents also were presented a list of potential barriers. The greatest barriers were lack of time (92\%), reimbursement issues (91\%), and lack of expertise (74\%) (Table 6).

\section{Discussion}

Among the first group of practices recognized under NCQA's PCMH program, $>40 \%$ had behavioral health clinicians on site, and half reported using evidence-based guidelines for mental health/ substance abuse conditions. Practices reported more frequent processes for coordination and referral and that they work better for medical specialists than for behavioral health. Thus this survey shows that the PCMH's promise for better integration of behavioral health with general medical care is partially fulfilled. There are limited data concerning the prevalence of behavioral health providers in primary care organizations and clinics. The only available estimates focus on FQHCs, where there is a mandate to provide behavioral health care. As noted earlier, Lardiere et $\mathrm{al}^{6}$ report that $70 \%$ of $\mathrm{FQHCs}$ provide behavioral services, $20 \%$ provide substance abuse services, and $20 \%$ provide both. Therefore, this survey seems to be

\section{Table 2. Frequency of Behavioral Health Providers in} Patient-Centered Medical Home Practices

Behavioral Health Provider Practices (\%)

Any behavioral health clinician on site 42 Case manager 62

Psychiatrist 16

Psychologist 22

Social Worker 25

Substance abuse clinician 
Table 3. Comparison of Referral Processes for Behavioral Health versus Other Medical Subspecialty among Patient-Centered Medical Home practices

\begin{tabular}{|c|c|c|c|c|c|}
\hline \multirow[b]{2}{*}{ Process } & \multicolumn{5}{|c|}{ Practices Reporting That They Have a Standardized Process (\%) } \\
\hline & $\mathrm{MH} / \mathrm{SA}$ & Cardiology & $\begin{array}{c}P \text { Value } \\
\text { (MH/SA vs } \\
\text { Cardiology) }\end{array}$ & Endocrinology & $\begin{array}{c}P \text { Value } \\
(\mathrm{MH} / \mathrm{SA} \text { vs } \\
\text { Endocrinology) }\end{array}$ \\
\hline Processing referrals & 84 & 91 & .006 & 90 & .01 \\
\hline Tracking referrals & 75 & 85 & .001 & 83 & .003 \\
\hline $\begin{array}{l}\text { Providing patient history and other } \\
\text { information to specialists }\end{array}$ & 83 & 96 & .0006 & 96 & .0006 \\
\hline $\begin{array}{l}\text { Receiving consultation reports from } \\
\text { specialists }\end{array}$ & 77 & 96 & $<.0001$ & 96 & .0001 \\
\hline $\begin{array}{l}\text { Helping patients schedule appointments } \\
\text { with specialists outside the practice }\end{array}$ & 78 & 87 & .04 & 84 & .24 \\
\hline
\end{tabular}

MH/SA, mental health/substance abuse.

the first published report of the characteristics of practices focused on behavioral health across multiple primary care settings. Our results also raise questions about who should be providing the variety of behavioral services needed in primary care. Among these PCMH practices, care managers are much more likely to provide support for behavioral health care than behavioral health specialty clinicians. There is a debate in the field about the competencies needed to provide behavioral services within primary care. ${ }^{14}$ Often, primary care patients need behavioral interventions to optimize clinical effect and reduce costs, ${ }^{15}$ but these types of interventions are frequently outside the training and experience of most behavioral health clinicians. More research on the best way to meet needs in these settings is needed.

Of particular concern is the finding that practices do not apply the same structure for organizing care for behavioral health conditions as they do for

Table 4. Results for Mental Health Organization Index

\begin{tabular}{|c|c|c|c|}
\hline \multirow[b]{2}{*}{ Organizational Items } & \multicolumn{3}{|c|}{ Practices Reporting Each Organizational Item (\%) } \\
\hline & $\begin{array}{l}\text { Yes, Works } \\
\text { Well }\end{array}$ & $\begin{array}{l}\text { Yes, Needs } \\
\text { Improvement }\end{array}$ & No \\
\hline \multicolumn{4}{|l|}{ Use of formal screening tool for: } \\
\hline Depression and/or other mental health problems & 46 & 34 & 20 \\
\hline Alcohol problems & 39 & 32 & 29 \\
\hline Substance use problems & 33 & 32 & 36 \\
\hline ADHD in children or adults & 34 & 24 & 42 \\
\hline Standardized process to make referrals to $\mathrm{MH} /$ substance use providers & 50 & 33 & 16 \\
\hline Standardized process to track referrals to $\mathrm{MH} /$ substance use providers & 33 & 41 & 25 \\
\hline $\begin{array}{l}\text { Regularly provide patient history and other information to } \\
\mathrm{MH} / \text { substance use providers }\end{array}$ & 59 & 25 & 16 \\
\hline $\begin{array}{l}\text { Regularly receive consultation reports from } \mathrm{MH} / \text { substance use } \\
\text { providers }\end{array}$ & 34 & 43 & 23 \\
\hline \multirow{2}{*}{$\begin{array}{l}\text { Help patients schedule outside appointments with } \mathrm{MH} / \text { substance use } \\
\text { providers }\end{array}$} & 41 & 37 & 22 \\
\hline & \multicolumn{2}{|c|}{ Yes (2 points) } & No (0 points) \\
\hline Has at least one mental health clinician at the practice & \multicolumn{2}{|c|}{42} & 58 \\
\hline $\begin{array}{l}\text { Scheduling of appointments with mental health clinicians at the } \\
\text { practice in same manner as medical appointments }\end{array}$ & \multicolumn{2}{|c|}{36} & 64 \\
\hline Availability of same-day appointments with a mental health clinician & & & 72 \\
\hline Mental Health Organizational Index, mean (SD) & \multicolumn{3}{|c|}{$12.3(5.6)$} \\
\hline
\end{tabular}

ADHD, attention deficit hyperactivity disorder; $M H$, mental health; SD, standard deviation. 


\begin{tabular}{|c|c|c|c|c|}
\hline & \multicolumn{2}{|c|}{$\begin{array}{l}\text { Mental Health Organizational } \\
\text { Index }\end{array}$} & \multicolumn{2}{|c|}{ Mental Health Clinical Index } \\
\hline & $\begin{array}{l}\text { Mean } \\
(\mathrm{SD})\end{array}$ & $\begin{array}{l}P \text { Value (Difference } \\
\text { across Categories }\end{array}$ & $\begin{array}{l}\text { Mean } \\
(\mathrm{SD})\end{array}$ & $\begin{array}{l}P \text { Value (Difference } \\
\text { across Categories) }\end{array}$ \\
\hline Ownership/affiliation & & .07 & & .75 \\
\hline Physician owned $(\mathrm{n}=61,61)$ & $11.4(5.5)$ & & $7.8(5.0)$ & \\
\hline Other $(\mathrm{n}=49,49)$ & $13.4(5.9)$ & & $7.5(5.4)$ & \\
\hline Practice size & & .30 & & .95 \\
\hline$<5$ Physicians $(\mathrm{n}=66,65)$ & $11.9(5.3)$ & & $7.6(5.3)$ & \\
\hline$\geq 5$ Physicians $(\mathrm{n}=53,51)$ & $12.9(5.7)$ & & $7.5(5.1)$ & \\
\hline NCQA patient-centered medical home recognition & & .86 & & .11 \\
\hline Level 1 or $2(\mathrm{n}=53,51)$ & $12.2(5.6)$ & & $6.7(5.8)$ & \\
\hline Level $3(n=66,65)$ & $12.4(5.4)$ & & $8.2(4.6)$ & \\
\hline Insurance mix & & $<.0001$ & & .003 \\
\hline $\begin{array}{l}\leq 20 \% \text { of patients with Medicaid or other public insurance } \\
\text { or no insurance }(n=63,63)\end{array}$ & $10.4(5.4)$ & & $6.6(4.7)$ & \\
\hline $\begin{array}{l}>20 \% \text { of patients with Medicaid or other public insurance } \\
\text { or no insurance }(n=41,41)\end{array}$ & $14.9(5.4)$ & & $9.7(5.4)$ & \\
\hline
\end{tabular}

NCQA, National Committee for Quality Assurance.

general medical conditions. Core practice flow issues such as scheduling, communication, and use of electronic health records in behavioral health are not treated in the same way as other medical subspecialties. This suggests that there is still a need for a fundamental change if care for mental health, substance abuse, and health behavior is to be included in the ongoing evolution of primary care. Furthermore, efforts to identify patients with mental health/substance abuse/behavioral health problems are limited. It is also concerning that within behavioral health, the focus on substance abuse and health behavior issues lag behind mental health. To achieve "triple aim" outcomes, primary care needs to change the current state of affairs, where mental health and substance abuse and health behavior providers and services are largely independent and separated. The evidence shows that the need for

Table 6. Obstacles That Limit Mental Health, Substance Abuse, and Health Behavior Implementation Somewhat or a Lot

\begin{tabular}{lc}
\hline Obstacles & Practices (\%) \\
\hline Lack of time & 92 \\
Lack of reimbursement & 91 \\
Lack of expertise & 74 \\
Lack of space & 51 \\
\hline
\end{tabular}

substance abuse and health behavior services focusing on lifestyle change and active participation in care is just as great a problem as mental health issues and has as much an effect on health status and function. ${ }^{16}$

\section{Limitations}

These findings are from the first iteration of NCQA PCMH standards; based in part on these results, NCQA's more recent standards have increased expectations for practices to focus organization on behavioral health conditions. We cannot ensure the representativeness of the sample even among NCQA PCMHs; within multisite practices we sampled the largest practice, leaving the impact of the nonselected practices on overall response unknown. PCMHs are not generalizable to all primary care. The survey, though it had face validity across 3 different research groups involved in primary care and integration, has not been sufficiently validated. A lack of survey results from non-PCMH practice settings and the maturing of earlier certified practices, as well as changing expectations in more recent levels of NCQA standards, limit the ability to put these results into larger context. In addition, this is the first survey to generate a snapshot of behavioral health in a sample of primary are practices. 
Our findings suggest that there is substantial opportunity to improve how PCMHs and other primary care practices address the behavioral health needs of their patients. Respondents indicated that barriers of time, resources, and lack of expertise affect their ability to adequately address behavioral health needs. Research and demonstration efforts are needed to understand which models of behavioral health integration are most effective. Sponsors such as the National Institutes of Health and Agency for Healthcare Research and Quality, other research supporters, as well as Medicaid, Medicare, other insurers, and policy makers need to make work in these areas of primary care reform and provide support (including successful models) and tools to make it happen. Changes in health care financing are especially needed. Practices reported that lack of reimbursement was the greatest barrier to mental health and substance use care. Payment models, including accountable care organizations that specifically call for better integration with behavioral health and that measure this particular aspect of care delivery are needed to provide the incentive for practices to make investments in better integration.

Nonetheless, it is increasingly clear that lack of access and inattention to mental health, substance abuse, and health behavior needs of primary care patients is costly in medical outcomes as well as dollars, ${ }^{17}$ and, as of yet, we are not prepared to deal with these issues at the practice or larger systems level. Increasing expectations for PCMH implementation is an important step in highlighting the need for better systems to support behavioral health care. The increased expectations for addressing behavioral health needs in NCQA's PCMH program, including greater focus on integration of care and care management for people with behavioral health needs, are a move in the right direction.

Our results suggest a series of next steps, some of which are in development. We need to survey a larger, more representative set of primary care practices including both $\mathrm{PCMH}$ and non-PCMH practices. Before we do so we need a validated measure of integration. The lead author (RK) and colleagues are currently validating a measure of integration drawn both from this initial survey and from Peek's ${ }^{18}$ paradigm case of collaborative care. Initial analyses from that measure suggest consid- erable interpractice variation, even in practices that identify themselves as integrated.

\section{Conclusion}

Currently, there are multiple experiments in different clinical and financial models of behavioral health in primary care. Despite the plethora of novel models of behavioral health interventions, there are few data to indicate whether they are effective or what elements of the models affect triple aim outcomes. There are emerging opportunities for that investigation. While many have determined that integrated care is a good idea, we need to go beyond the good idea and respond to various issues: What does integration look like in practices? Which patients use it? What elements and models are most effective? Does the cost of the transformation justify the investment? This survey is really the first step toward responding to these questions.

\section{References}

1. Borowsky SJ, Rubenstein LV, Meredith LS, Camp $\mathrm{P}$, Jackson-Triche M, Wells KB. Who is at risk of nondetection of mental health problems in primary care? J Gen Intern Med 2000;15:381-8.

2. Wang PS, Lane M, Olfson M, Pincus HA, Wells $\mathrm{KB}$, Kessler RC. Twelve-month use of mental health services in the United States: results from the $\mathrm{Na}$ tional Comorbidity Survey Replication. Arch Gen Psychiatry 2005;62:629-40.

3. Wang PS, Aguilar-Gaxiola S, Alonso J, et al. Use of mental health services for anxiety, mood, and substance disorders in 17 countries in the WHO world mental health surveys. Lancet 2007;370:841-50.

4. Phelps R, Eisman EJ, Kohout J. Psychological practice and managed care: results of the CAPP practitioner survey. Prof Psychol Res Pr 1998;29:31-6.

5. Kathol RG. Prevalence of behavioral health providers in primary care. Paper presented at Virginia Primary Care Association Conference on Integrating Primary Care, March 2009, Richmond, Virginia.

6. Lardiere MR, Jones E, Perez M. National Association of Community Health Centers 2010 assessment of behavioral health services provided in federally qualified health centers. Bethesda, MD: National Association of Community Health Centers; 2011.

7. Kessler RC, Demler O, Frank RG, et al. Prevalence and treatment of mental disorders, 1990 to 2003. N Engl J Med 2005;352:2515-23.

8. Croghan TW, Brown JD. Integrating mental health treatment into the patient centered medical home. Rockville, MD: Agency for Healthcare Research and Quality; 2010. 
9. Baird M, Blount A, Brungardt S, et al. The development of joint principles: integrating behavioral health care into the patient-centered medical home. Ann Fam Med. 2014;12:183.

10. Butler M, Kane RL, McAlpin D, et al. Integration of mental health/substance abuse and primary care, no. 173. AHRQ publication no. 09-E003. Rockville, MD: Agency for Healthcare Research and Quality; 2008.

11. Patient-Centered Outcomes Research Institute (PCORI). Integration of mental health and primary care. Paper presented at: PCORI Workgroup Webinar, Washington, DC. February 2013.

12. Han E, Scholle SH, Morton S, Bechtel C, Kessler R. Survey shows that fewer than a third of patientcentered medical home practices engage patients in quality improvement. Health Aff (Millwood) 2013; 32:368-75.

13. Peek CJ. Planning care in the clinical, operational, and financial worlds. In: Kessler R, Stafford D, eds.
Collaborative medicine case studies. New York: Springer; 2008:25-38.

14. McDaniel SH, Grus CL, Cubic BA, et al. Competencies for psychology practice in primary care. Am Psychol 2014;69:409-29.

15. Blount A, Schoenbaum M, Kathol R, et al. The economics of behavioral health services in medical settings: a summary of the evidence. Prof Psychol Res Pr 2007;38:290-7.

16. Fisher EB, Fitzgibbon ML, Glasgow RE, et al. Behavior matters. Am J Prev Med 2011;40:e15-30.

17. Kessler R, Stafford D. Primary care is the de facto mental health system. In: Kessler R, Stafford D, eds. Collaborative medicine case studies. New York: Springer; 2008:9-21.

18. Peek CJ. A collaborative care lexicon for asking practice and research development questions. Presented at the Collaborative Care Research Network Research Development Conference, 2009, Denver, CO. 


\section{Appendix 1}

\section{The Complete Survey}

1. Does your practice regularly use a formal screening tool to identify the following conditions?

\begin{tabular}{lcc}
\hline & Yes, works & Yes, needs \\
improvement
\end{tabular}

a. Depression and/or other mental health problems

b. Alcohol problems

c. Substance use problems

d. ADHD in children or adults

2. Does your practice regularly use a standardized process to make referrals to the following specialties:

\begin{tabular}{cccc}
\hline & Yes, works & Yes, needs \\
well & improvement & No \\
\hline
\end{tabular}

c. Mental health and substance use providers

3. Does your practice regularly use a standardized process to track referrals to the following specialties:

\begin{tabular}{cccc}
\hline & Yes, works & Yes, needs \\
improvement & well \\
\hline
\end{tabular}

c. Mental health and substance use providers

4. Does your practice regularly provide patient history and other information to the following kinds of specialists when they are involved in your patients' care?

\begin{tabular}{cccc}
\hline & Yes, works & Yes, needs \\
well & improvement & No \\
\hline
\end{tabular}

c. Mental health and substance use providers

5. Does your practice regularly receive consultation reports from the following specialties?

\begin{tabular}{cccc}
\hline & Yes, works & Yes, needs & \\
improvement & Nell & No \\
\hline
\end{tabular}

c. Mental health and substance use providers

6. Does your practice help patients schedule appointments with specialists outside the practice for the following specialties?

\begin{tabular}{cccc}
\hline & Yes, works & Yes, needs & \\
Noll & improvement & No
\end{tabular}

c. Mental health and substance use providers

7. Which of the following clinicians or staff work in your practice? Yes to any of the below choices constituted 2 points $(2$ points maximum).

No
a. Psychiatrists
b. Psychologist (doctoral level)
c. Therapist/counselor (master's level)
d. Social worker
e. Certified substance use counselor
f. Care manager (any discipline)

8. If you have mental health clinicians working in your practice:

\begin{tabular}{lcc}
\hline & Yes & No \\
\hline a. Is scheduling handled in the same manner as patient medical appointments? & $\square$ & $\square$ \\
b. Are same-day appointments regularly available? & $\square$ & $\square$
\end{tabular}




\begin{tabular}{|c|c|c|c|}
\hline & $\begin{array}{l}\text { Yes, it } \\
\text { works well }\end{array}$ & $\begin{array}{l}\text { Yes, but it needs } \\
\text { improvement }\end{array}$ & No \\
\hline $\begin{array}{l}\text { 9. Has your practice adopted evidence-based treatment protocols } \\
\text { for mental health or substance use conditions (eg, stepped care } \\
\text { for depression)? }\end{array}$ & $\square$ & $\square$ & $\square$ \\
\hline \multicolumn{4}{|l|}{ 10. For patients with depression, does your practice: } \\
\hline $\begin{array}{l}\text { a. Use a standardized tool to monitor depression symptoms, } \\
\text { severity or response to treatment? }\end{array}$ & $\square$ & $\square$ & $\square$ \\
\hline $\begin{array}{l}\text { b. Does your practice regularly record results from depression } \\
\text { screening and monitoring tool(s) in an electronic data system? }\end{array}$ & $\square$ & $\square$ & $\square$ \\
\hline $\begin{array}{l}\text { 11. Does your practice regularly use structured health behavior } \\
\text { change protocols for treating the following symptoms: }\end{array}$ & $\begin{array}{l}\text { Yes, it } \\
\text { works well }\end{array}$ & $\begin{array}{l}\text { Yes, but it needs } \\
\text { improvement }\end{array}$ & No \\
\hline a. Insomnia (eg, consistency training) & $\square$ & $\square$ & $\square$ \\
\hline b. Headaches (eg, relaxation response) & $\square$ & $\square$ & $\square$ \\
\hline c. Obesity (eg, exercise adherence) & $\square$ & $\square$ & $\square$ \\
\hline d. Smoking cessation (eg, nicotine replacement therapy) & $\square$ & $\square$ & $\square$ \\
\hline 12. In the past 12 months, has your practice: & & Yes & No \\
\hline
\end{tabular}

a. Collected clinical process and outcome measures for one or more mental health or substance use conditions?

b. Used mental health or substance use performance data as part of a practice quality improvement initiative?

13. Thinking about mental health and substance use care for your patients, how much of a barrier to your practice are the following?

A lot Somewhat Not at all
a. Lack of time
b. Lack of reimbursement/funding
c. Lack of expertise/knowledge in effective approaches
d. Lack of space

14. We are interested in how your practice learns about the needs and experiences of your patients and their families. Please tell us about how often you use the following methods for patient/family input.

At least once Have not done
$\begin{aligned} & \text { More than once Once in the but not in but plan to do Do not plan } \\ & \text { in the past year past year the past year }\end{aligned}$ so
to do

a. Conducted a patient/family survey

b. Asked for patient/family input through interview, meeting, or focus group

c. Conducted a "walk-through" of the practice to get patient/family view of how the practice works

d. Asked patients/families for input on written documents such as patient materials or website

e. Obtained comments through a "suggestion box" or other ad hoc approach

f. Convened a patient/family advisory council

g. Included patients/family members on a quality improvement or practice redesign team

h. Appointed individual patient/family advisors

i. Other? (Please describe) 
15. What patient/family survey tool has your practice used? (check all that apply):

\section{$\square$ CAHPS}

$\square$ Another standardized survey

$\square$ A tool your practice developed

$\square$ Do not know which tool was used

$\square$ Our practice has not participated in a patient/family survey (please skip to question 16)

15a. How was patient/family survey data collected?

$\square$ My practice collected data

$\square$ External organization collected data

$\square$ Don't know

$15 \mathrm{~b}$. Did your survey include questions about mental health or emotional concerns?

$\square$ Yes

$\square$ No

$\square$ Don't know

16. At how many locations does your organization see patients?

17. What is the total number of each of the following personnel employed at your practice? If unsure, provide your best estimate.

\# of

\# of FTEs individuals

a. Primary care physicians

b. Specialty care physicians

c. Other clinicians who have their own panel of patients (NPs, PAs)

18. Please give your best estimate of the percentage of primary care patients in your practice whose care is covered by (primary payer only).

a. Commercial or private insurance

b. Medicare

c. Medicaid or other public insurance

d. Uninsured

e. Other

19. Who owns your practice?

$\square$ Physicians in the organization

$\square$ Hospital/hospital system/health system

$\square$ HMO or other insurance entity

$\square$ Jointly owned (please specify):

$\square$ Government (federal/state/local)

$\square$ Other (please specify):

20. Who completed this survey?

$\square$ Physician

$\square$ Practice manager

$\square$ Nurse manager

$\square$ Other (please specify):

We would like to talk with some practices to get more information on their activities in areas discussed above. Please check if you would NOT want to be contacted.

$\square$ Do NOT contact

Contact: 


\section{Appendix 2}

Questions in the Mental Health Organizational Index

1. Does your practice regularly use a formal screening tool to identify the following conditions?

\begin{tabular}{ccc}
\hline & Yes, works & Yes, needs \\
well & improvement & No \\
\hline
\end{tabular}

a. Depression and/or other mental health problems

b. Alcohol problems

c. Substance use problems

d. ADHD in children or adults

2. Does your practice regularly use a standardized process to make referrals to the following specialties:

\begin{tabular}{cccc}
\hline & Yes, works & Yes, needs \\
well & improvement & No \\
\hline
\end{tabular}

c. Mental health and substance use providers

3. Does your practice regularly use a standardized process to track referrals to the following specialties:

\begin{tabular}{cccc}
\hline & Yes, works & Yes, needs \\
improvement & Nell \\
\hline
\end{tabular}

c. Mental health and substance use providers

4. Does your practice regularly provide patient history and other information to the following kinds of specialists when they are involved in your patients' care?

\begin{tabular}{cccc}
\hline & Yes, works & Yes, needs \\
improvement & Nell \\
\hline
\end{tabular}

c. Mental health and substance use providers

5. Does your practice regularly receive consultation reports from the following specialties?

\begin{tabular}{cccc}
\hline & Yes, works & Yes, needs & \\
improvement & Noll & No \\
\hline
\end{tabular}

c. Mental health and substance use providers

6. Does your practice help patients schedule appointments with specialists outside the practice for the following specialties?

\begin{tabular}{cccc}
\hline & Yes, works & Yes, needs \\
improvement & No \\
\hline
\end{tabular}

c. Mental health and substance use providers

7. Which of the following clinicians or staff work in your practice? Yes to any of the below choices constituted 2 points $(2$ points maximum).

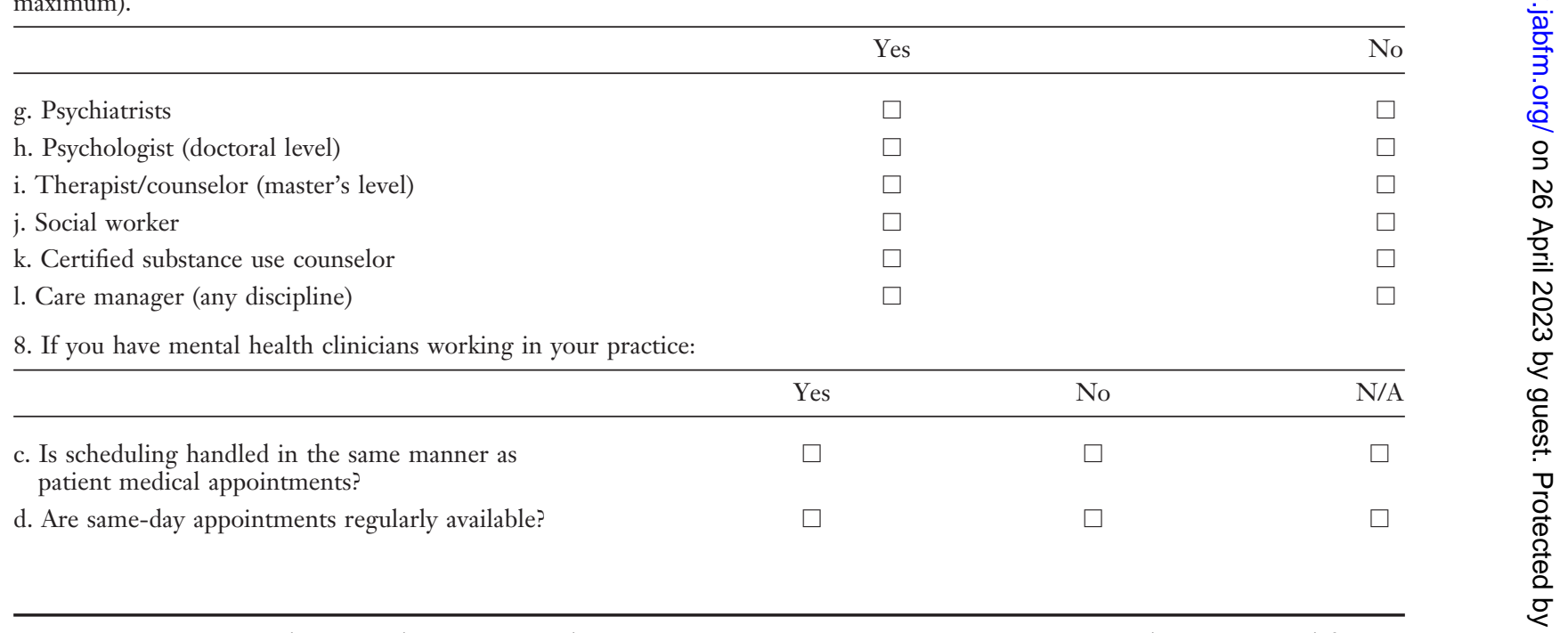




\begin{tabular}{|c|c|c|c|}
\hline & \multicolumn{3}{|c|}{ Practices Reporting Each Organizational Item (\%) } \\
\hline & $\begin{array}{l}\text { Yes, Works } \\
\text { Well }\end{array}$ & $\begin{array}{l}\text { Yes, Needs } \\
\text { Improvement }\end{array}$ & No \\
\hline $\begin{array}{l}\text { Use of evidence-based treatment protocols for mental health or } \\
\text { substance use conditions }\end{array}$ & 20 & 34 & 46 \\
\hline $\begin{array}{l}\text { Use of standardized tool for monitoring depression symptoms, severity, } \\
\text { or response to treatment }\end{array}$ & 35 & 40 & 25 \\
\hline $\begin{array}{l}\text { Regular recording of depression screening and monitoring tools in an } \\
\text { electronic data system }\end{array}$ & 35 & 27 & 38 \\
\hline \multicolumn{4}{|l|}{ Use of structured health behavior change protocols for } \\
\hline Insomnia & 13 & 25 & 62 \\
\hline Headaches & 10 & 24 & 66 \\
\hline Obesity & 23 & 36 & 41 \\
\hline \multirow[t]{2}{*}{ Smoking } & 37 & 34 & 29 \\
\hline & \multicolumn{2}{|c|}{$\%$ Yes (2 points) } & $\%$ No (0 points) \\
\hline $\begin{array}{l}\text { Collected clinical measures for one or more mental health/substance use } \\
\text { conditions in past } 12 \text { months }\end{array}$ & \multicolumn{2}{|c|}{32} & 68 \\
\hline $\begin{array}{l}\text { Used mental health or substance use performance data in practice quality } \\
\text { improvement in past } 12 \text { months }\end{array}$ & \multicolumn{2}{|c|}{32} & 68 \\
\hline Mental Health Clinical Index, mean (SD) & \multicolumn{3}{|c|}{$7.6(5.1)$} \\
\hline
\end{tabular}

Questions in Mental Health Treatment Index

\begin{tabular}{|c|c|c|c|}
\hline & $\begin{array}{c}\text { Yes, It } \\
\text { Works Well }\end{array}$ & $\begin{array}{l}\text { Yes, But It Needs } \\
\text { Improvement }\end{array}$ & No \\
\hline $\begin{array}{l}\text { 9. Has your practice adopted evidence-based treatment protocols for mental health } \\
\text { or substance use conditions (eg, stepped care for depression)? }\end{array}$ & $\square$ & $\square$ & $\square$ \\
\hline \multicolumn{4}{|l|}{ 10. For patients with depression, does your practice } \\
\hline $\begin{array}{l}\text { c. Use a standardized tool to monitor depression symptoms, severity, or response } \\
\text { to treatment? }\end{array}$ & $\square$ & $\square$ & $\square$ \\
\hline $\begin{array}{l}\text { d. Does your practice regularly record results from depression screening and } \\
\text { monitoring tool(s) in an electronic data system? }\end{array}$ & $\square$ & $\square$ & $\square$ \\
\hline $\begin{array}{l}\text { 11. Does your practice regularly use structured health behavior change protocols } \\
\text { for treating the following symptoms? }\end{array}$ & $\begin{array}{l}\text { Yes, it } \\
\text { works well }\end{array}$ & $\begin{array}{l}\text { Yes, but it needs } \\
\text { improvement }\end{array}$ & No \\
\hline e. Insomnia (eg, consistency training) & $\square$ & $\square$ & $\square$ \\
\hline f. Headaches (eg, relaxation response) & $\square$ & $\square$ & $\square$ \\
\hline g. Obesity (eg, exercise adherence) & $\square$ & $\square$ & $\square$ \\
\hline h. Smoking cessation (eg, nicotine replacement therapy) & $\square$ & $\square$ & $\square$ \\
\hline 12. In the last 12 months, has your practice: & & Yes & No \\
\hline $\begin{array}{l}\text { a. Collected clinical process and outcome measures for one or more mental health } \\
\text { or substance use conditions? }\end{array}$ & & $\square$ & $\square$ \\
\hline $\begin{array}{l}\text { b. Used mental health or substance use performance data as part of a practice } \\
\text { quality improvement initiative? }\end{array}$ & & $\square$ & $\square$ \\
\hline
\end{tabular}

